https://doi.org/10.1037/drm0000157

\title{
Association between Recurrent Dreams, Disturbing Dreams and Suicidal Ideation in Adolescents
}

(C)American Psychological Association, 2021. This paper is not the copy of record and may not exactly replicate the authoritative document published in the APA journal.

Please do not copy or cite without author's permission. The final article is available, upon publication, at: https://doi.org/10.1037/drm0000157

Aline Gauchat ${ }^{1,2}$, Ph.D., Antonio Zadra ${ }^{1}$, Ph.D., Mira El Hourani ${ }^{1,2}$, B.Sc., Sophie Parent $^{2,3}$, Ph.D., Johanne Renaud ${ }^{4,5}$, Ph.D., Richard E. Tremblay ${ }^{1,2,6,7,8}$, Ph.D., \& Jean R. Séguin ${ }^{2,9^{*}}$, Ph.D.

${ }^{1}$ Department of Psychology, Université de Montréal, Montréal, Québec, Canada;

${ }^{2}$ Centre de recherche du CHU Ste-Justine, Montréal, Québec, Canada;

${ }^{3}$ School of psychoeducation, Université de Montréal, Montréal, Québec, Canada;

${ }^{4}$ McGill Group for Suicide Studies, Department of Psychiatry, Douglas Mental Health University Institute, McGill University, Montréal, Québec, Canada;

${ }^{5}$ Manulife Centre for Breakthroughs in Teen Depression and Suicide Prevention, Montréal, Canada, Montréal, Québec, Canada;

${ }^{6}$ Department of Pediatrics, Université de Montréal, Montréal, Québec, Canada;

${ }^{7}$ School of Public Health, Physiotherapy and Population Science, University College Dublin, Ireland;

${ }^{8}$ INSERM U669, Paris, France;

${ }^{9}$ Department of Psychiatry and Addictology, Université de Montréal, Montréal, Québec, Canada

*Correspondence: Dr Jean R. Séguin; jean.seguin@ umontreal.ca; Centre de recherche du CHU Ste-Justine; Bureau B17.107; 3175 chemin Côte Ste-Catherine, Montréal, Québec, H3T 1C5; 5143454937 ext. 4043. 
Conflict of interests. The authors declare that the research was conducted in the absence of any commercial or financial relationships that could be construed as a potential conflict of interest.

Author contributions. AG contributed to study design, analyzed the results, and wrote the manuscript draft. AZ obtained supporting grants, supervised the study, contributed to the statistical analyses, and reviewed the manuscript. MEH reviewed the data acquisition and contributed to manuscript revision. SP, JR, and RET contributed to the study design, data collection, and reviewed the manuscript. JRS obtained supporting grants, designed and supervised the study, contributed to the statistical analyses, and reviewed the manuscript. All authors, read and approved the submitted version of the manuscript. Funding. The longitudinal study from which these data were collected was funded by the Canadian Institutes for Health Research via a scholarship to AG, a fellowship to JRS, grant MOP 44072 to JRS and grant MOP-97910 to JRS and SP; the Fonds Maria et Georginia Daoussis and the Department of Psychology Université de Montréal to MEH; the Fonds Monique Gaumond provided 2 awards to AG and one to JRS; the Fonds de Recherche en Santé du Québec via the Réseau Santé Mentale du Québec (Québec Mental Health Network), via fellowships to JRS, grant 981055 to JRS and RET, and grant 991027 to JRS; the Social Sciences and Humanities Research Council of Canada via a scholarship to MEH, grant 839-2000-1008 to RET, JRS and SP, grant 410-99-1048 to SP, and grant 839-2000-1008 to AZ; the Canadian Institutes of Health Research, grant MOP 97865 to AZ; and the Fonds Québécois pour la recherche sur la Société et la Culture grants 2002-RS-79238 and 2009-RG-124779.

Acknowledgements. This article was adapted from a study contained in the first author's doctoral thesis entitled "Rêves dysphoriques et rêves récurrents chez les enfants et les adolescents : investigations cliniques et corrélats psychosociaux." The authors are grateful to Charles-Édouard Giguère for data management and statistical analyses, and to our partner, the Institut de la Statistique du Québec. We thank all the parents and children for their generous participation in the study. 


\title{
Association between Recurrent Dreams, Disturbing Dreams and Suicidal Ideation in Adolescents
}

\begin{abstract}
Disturbing dreams and recurrent dreams have both been linked to a wide range of psychological difficulties in children. There is growing evidence that the experience of frequent disturbing dreams is associated with suicidal ideation in adults but studies in young adolescents have been limited and the results inconsistent. In addition, the possible relationship between suicidal ideation and recurrent dreams has yet to be studied. We thus investigated the relation between disturbing dreams, recurrent dreams and suicidal ideation in a sample of young adolescents. Self-report measures of disturbing dream frequency, recurrent dream frequency, and suicidal ideation were collected at age 12 years and again at age 13 years from 170 children from a prospective population-based birth cohort. While the rate of disturbing dreams and recurrent dreams dropped between ages 12 and 13, the rate of self-reported suicidal ideation increased between the ages of 12 and 13 years. Analyses taking sex and age into account revealed that young adolescents who reported having had suicidal thoughts over the past year had significantly greater frequencies of disturbing dreams and of recurrent dreams than adolescents who had not thought about suicide. These findings highlight the potential clinical value of assessing disturbing and recurrent dreams as part of the screening process for suicidal ideation in young adolescents.
\end{abstract}

Keywords: Dreaming, Recurrent dreams, Nightmares, Suicidal ideation, Adolescence 
Association between Recurrent Dreams, Disturbing Dreams and Suicidal Ideation in Adolescents

Disturbing dreams (DD) are vivid dreams marked by intense negative emotions such as fear, sadness and anger (Gauchat et al., 2020; Nielsen \& Levin, 2007; Robert \& Zadra, 2014). Research on the correlates of DD in adolescents has been inspired by studies of adults in whom these relations have been investigated at length (Levin \& Nielsen, 2007; Sandman et al., 2013). DD, including bad dreams and nightmares, are frequently experienced by children and adolescents (Gauchat et al., 2014; Gauchat et al., 2009; Ophoff et al., 2018) and their occurrence is linked to a range of psychological difficulties, including anxiety, depression and behavioural difficulties (Gauchat et al., 2014; Gauchat et al., 2020; Simard et al., 2008). One meta-analysis showed that frequent DD are positively associated with suicidal ideation in adults (Pigeon et al., 2012) and DD is the sleep-related problem most strongly associated with suicidal risk in people having attempted suicide (Michael R. Nadorff et al., 2014; Sjöström et al., 2009). Similar results have been obtained in non-clinical adult populations (Bernert et al., 2017; Cukrowicz et al., 2006; Sandman et al., 2013).

Few studies, however, have examined these relations in adolescents. This lack of information is an important gap given that suicide constitutes a major public health concern and that suicide attempts increase markedly during adolescence (Brezo et al., 2008; Gould et al., 2003; Nock et al., 2013; Patton et al., 2009; Perou et al., 2013) and several authors have expressed concerns about the lack of studies on DD and suicidality in younger populations (Abe \& de Kernier, 2013; Bernert \& Joiner, 2007; Liu \& Buysse, 2006; Russell et al., 2018). Identifying correlates of suicidal ideation in adolescents is particularly important since this population is often reluctant to share or report their suicidal thoughts (Bernert et al., 2015; Britto et al., 2010; Lothen-Kline et al., 2003; Russell et al., 2018). Moreover, about one third of individuals experiencing suicidal ideations will plan a suicide, and 56\% will make an attempt (Nock et al., 2008; Nock et al., 2013).

Furthermore, the few existing studies focusing on adolescent populations have yielded inconsistent results. One study (Choquet \& Menke, 1990) of European adolescents aged between 13 and 16 found a significant association between frequent DD and suicidal ideation. Similarly, one study (Liu, 2004) of Asian adolescents aged between 12 to 18 found that those who reported having DD "sometimes" or "often" were 2 to 3 times more likely to report suicidal ideation than were those who rarely had DD.

Moreover, the association between DD and suicidal ideation remained significant even after controlling for depression. By contrast, one study (Roberts \& Lennings, 2006) of Australian adolescents between 12 and 18 years of age found that DD frequency was not significantly associated with suicidal ideation. As this finding was secondary to the study's main goals, no explanations were provided for this result.

In one prospective study (Wong et al., 2011) of American children, only "having trouble sleeping", but not the occurrence of DD, between the ages of 12 and 14 predicted suicidal thoughts at ages 15 to 17 when common risk factors and other sleep problems were controlled for. More recently, one study (Stanley et al., 2017) of children between the ages of 6 to 15 years suffering from a bipolar disorder found that after controlling for depression, trauma history and generalized anxiety disorder, those presenting with a 
lifetime history of nightmare disorder had a two-fold increase in their risk for suicide. Finally, in a cross-sectional study of 15 to17 year-old adolescents, those reporting clinically salient nightmares were found to have a three-fold increase in suicidal ideation (Russell et al., 2018).

Although the contents of DD tend to vary over time, recurrent dreams (RD) are defined as a class of dreams that reoccur over time while maintaining the same theme and content (Brown \& Donderi, 1986; Domhoff, 1993; Gauchat et al., 2015; Zadra et al., 2006). Only about $75 \%$ of recurrent dreams are described as being negatively toned, with another $10 \%$ containing a mixture of positive and negative emotions (Zadra et al., 2006). Studies in adults converge in showing that people reporting RD obtain higher scores on measures of depression, anxiety, neuroticism and stress events, than people without RD (Brown \& Donderi, 1986; Duke \& Davidson, 2002; Gauchat et al., 2015; Kroth et al., 2002; Robbins \& Tanck, 1992; Zadra et al., 1998). Two studies of "general sleep-related experiences," a construct composed of several dream and sleep-related experiences, including recurrent dreams, found that these experiences were significantly more frequent in clinical groups than in control participants and that recurrent dreams correlated significantly with psychological distress (Soffer-Dudek \& Shahar, 2009; Soffer-Dudek et al., 2011).

More recently, a study of RD content, based on self-determination theory, found that these dreams were more likely to feature negative emotions in people experiencing "psychological need frustration" (Weinstein et al., 2018). Finally, the only study to have specifically examined the psychological correlates of recurrent dreams in adolescents found that by age 11, the presence of recurrent dreams was already associated with emotional difficulties in boys, but not necessarily in girls (Gauchat et al., 2009).

Studies have yet to investigate if recurrent dreams, much like DD, are also associated with suicidal ideation in adults or adolescent populations. The aim of the present study was to investigate the relations between DD, RD and suicidal ideation over a one year period in young adolescents between the ages of 12 and 13 years.

\section{Participants}

\section{Materials and Methods}

Participants were adolescents taking part in a broader longitudinal study focusing on the social, psychological and cognitive development of children from all urban socioeconomic backgrounds in Québec, Canada. At the study's inception, 1000 families of newborns were randomly selected from the 1996 birth register (Jetté et al., 1997). Of these, 572 accepted to participate in the original study and were subsequently assessed annually in French ( $\sim 82 \%$ ) or English (Canada's two official languages) from when their infants were age 5 months. Due to annual attrition, variability in the participants' year to year availability for data collection and budgetary constraints to maintain follow-up, a total of 216 children (comprised equally of boys and girls) completed the present study at age 12, and 195 at age 13 . These samples did not differ from the rest of the original sample of children in terms of socio economic level, including family income (at 12: $p=.10$; at 13: $p=.47$ ), family type (single parent or not) (at 12; $p=.60 ;$ at $13 p=.14$ ), and level of education of the child's mother (at 12: $p=.62$; at 13: $p=.60$ ). 


\section{Measures}

Presence of suicidal ideation and frequency of DD and RD were assessed within a battery of self-reported questionnaires. Suicidal ideation was assessed with the following item: "Over the past 12 months, did you ever seriously consider attempting suicide?" which has been extensively validated (Bolanis et al., 2020; Geoffroy et al., 2016; Marschall-Lévesque et al., 2017; Orri et al., 2020). When interacting with adolescents, the term "bad dreams" (defined as very disturbing dreams) was used to refer to DD as the broader construct of DD was too unfamiliar of a concept given the age of our participants. Adolescents were required to answer the question: "On average, how frequently do you have bad dreams?" using the following choices: "Never," "Sometimes," "Often," "Always," or "Don't know." Those reporting bad dreams were also asked to estimate the number of bad dreams experienced over the past month (Gauchat et al., 2020; Gauchat et al., 2009; Liu, 2004; Liu et al., 2017; Robert \& Zadra, 2008; Tanskanen et al., 2001). Responses for adolescents who reported "never" to the previous question were coded as 0 while a maximum frequency was set at 30 (i.e., 1 $\mathrm{DD} /$ day) to limit the impact of potential outliers. A one- month retrospective frequency estimate was used instead of a one year estimate as it has been shown to correspond more closely to prospectively-collected log-based frequency measures of DD from the same individual. An RD was defined as "a dream that, when recalled, gives you the impression that you had it before." Adolescents were asked whether or not they experienced a recurrent dream in the past 12 months and, if yes, had to report the frequency of their RD (Gauchat et al., 2020; Gauchat et al., 2009). Responses for adolescents who reported that they did not have RD were coded as 0 for the frequency variable.

\section{Procedure}

When the adolescents were aged 12 and 13 years, each parent or person responsible for the adolescent received an invitation to participate in the study along with a consent form. Appointments were then scheduled where research assistants met the caregivers and adolescents. Adolescent participants could complete the questionnaires confidentially which reduces response bias, (Britto et al., 2010; Lothen-Kline et al., 2003) and were provided with a list of adolescent-oriented resources. Research assistants were trained to implement a clinical follow up safety protocol devised by JR in case of a need - no request was made. The study was approved by the CHU Ste-Justine Research Center and the study protocol also complied with the ethical guidelines of the American Psychological Association (2017).

\section{Analyses}

Adolescents with or without suicidal ideation were compared using repeated measure (ages 12, and 13) mixed-effects model analyses in SPSS (Version 18) to investigate the relationships between DD, RD and suicidal ideation in two separate models. We chose a mixed-effects model as opposed to a traditional repeated-measure ANOVA as it allows for an unbalanced design. In a mixed-effects model, if data for one of the years is missing, the other year is still included in the analyses, whereas traditional repeated-measures ANOVA requires data from each time point for each participant to be entered in the analyses. Thus the mixed effect model actually uses all the available information for parameter estimation. Two different models were tested because even if DD and RD are not independent disorders, they represent two different constructs that share less than $4 \%$ of variance: the correlations between RD and DD at age 12 was .11 
$(p=.14)$, and $.21(p<.05)$ at age 13. Suicidal ideation was treated as a predictor variable; the covariates were sex and age while DD or RD frequencies were the dependent variables.

\section{Results}

The proportion of adolescents reporting suicidal ideation at ages 12 and 13 as well as group mean frequencies and standard deviations of DD and RD are presented in Table 1. The prevalence of suicidal ideation found in the current sample (Bolanis et al., 2020; Geoffroy et al., 2016; Marschall-Lévesque et al., 2017; Orri et al., 2020) was comparable to that of other studies for this age group (Breton et al., 2002). Another health survey examining adolescents aged 15 years old or older reported a gradual increase in suicidal ideations rates throughout adolescence (Camirand et al., 2016). The proportion of adolescents with DD was comparable to other studies although comparisons across studies is difficult because of methodological differences in DD assessment (Gauchat \& Zadra, 2012; Hasler \& Germain, 2009). As can be seen in Table 1, DD and RD frequencies decreased between the ages of 12 and 13. Conversely, the rate of selfreported suicidal ideation more than tripled between the ages of 12 and 13 years, which coincides with the transition from primary to secondary school.

Table 1

Descriptive Statistics of Disturbing Dreams, Recurrent Dreams and Suicidal Ideation.

\begin{tabular}{cccc}
$\begin{array}{c}\text { Age } \\
\text { (years) }\end{array}$ & $\begin{array}{c}\text { DD mean frequency } \\
(\mathrm{SD})\end{array}$ & $\begin{array}{c}\text { RD mean frequency } \\
(\mathrm{SD})\end{array}$ & $\begin{array}{c}\text { \% of adolescents with suicidal } \\
\text { ideation }\end{array}$ \\
\hline 12 & $2.5(3.1)$ & $1.0(2.4)$ & 2.8 \\
13 & $1.8(2.8)$ & $0.4(1.2)$ & 10.2 \\
\hline
\end{tabular}

In the first model of the relation between suicidal ideation on DD frequency we tested interactions with $\operatorname{sex}(\mathrm{p}=.21)$ and with age $(\mathrm{p}=.91)$ to verify the assumption of homogeneity of slopes, and both interactions were non-significant so were removed from the model. Sex and age therefore met criteria for being used as covariates in the model. The main effect of suicidal ideation was significant $F(1,315)=4.1, p<.05$ and so was the main effect of age $F(1,315)=5.43, p<.05$ whereas the main effect of sex was not significant $p=.27$. Adolescents had significantly fewer DD at age 13 than at age 12 (see table 1). Finally, adolescents without suicidal ideation had significantly fewer DD $(M=2.2$ ; $S D=3.0)$ than adolescents with suicidal ideation $(M=4.0 ; S D=3.2)$.

In the second model of the relation between suicidal ideation and RD frequency, we again tested interactions with sex $(p=.79)$ and with age $(p=.87)$ to verify the assumption of homogeneity of slopes, and both interactions were non-significant so were removed from the model. Sex and age were left as covariates in the model. The main effect of suicidal ideation was significant $F(1,337)=11.1, p<.05$ and so was the main effect of age $F(1,337)=20.67, p<.05$ whereas the main effect of sex was not significant $(\mathrm{p}=.35)$. Adolescents had significantly fewer RD at age 13 than at 12 (see Table 1). Also adolescents without suicidal ideation had significantly lower frequency of RD $(M=.6$; $S D=1.9)$ than adolescents with suicidal ideation $(M=2.8 ; S D=3.0)$ 


\section{Discussion}

This study is the first to report an association between self-reported frequencies of DD as well RD experiences and suicidal ideation in young adolescents. Specifically, our results indicate that by ages 12 and 13, and even after controlling for age and sex, young adolescents who reported having had suicidal ideations during the past 12 months experienced higher frequencies of DD and RD than those who had not thought about suicide. The results from our measures of DD frequency are consistent with findings described in adult populations (Becker et al., 2018; Bernert et al., 2017; Cukrowicz et al., 2006; Pigeon et al., 2012; Sjöström et al., 2009) as well as in some studies involving adolescents (Choquet \& Menke, 1990; Liu, 2004; Russell et al., 2018; Stanley et al., 2017). Furthermore, the present study, which was the first to investigate the relation between RD occurrence and suicidal ideation in any population, also revealed a significant link between these two variables in young adolescents.

With respect to the association between DD and suicidal ideation, since the content of everyday dreams in adults has been shown to reflect the conceptions we have of ourselves, of other people, and our ongoing concerns (Bulkeley, 2018; Domhoff, 2011, 2018; Pesant \& Zadra, 2006; Schredl \& Hofmann, 2003), the repeated experience of intensely negatively toned dreams during adolescence may be related to negative emotional turmoil experienced during wakefulness. It is also possible that this association is partially explained by the presumed role of non-disturbed dreaming in emotional regulation (Abe \& de Kernier, 2013; Levin et al., 2010; Littlewood et al., 2017; Scarpelli et al., 2019). In fact, dreaming (especially during REM sleep) may play a role in emotion regulation and thus contribute with a better waking adjustment. Finally, the directionality of the association between DD and impoverished well-being over a period of months or years may become bi-directional as it is also thought that negative dream content can adversely affect emotional states upon awakening in adults (Lancee \& Schrijnemaekers, 2013).

Given the mounting evidence linking DD to suicidal ideation, including in young adolescents, two clinical variables merit further study. First, the added value of including an assessment question on DD frequency in screening instruments targeting youth at risk of suicidal behaviors should be investigated. Second, the potential therapeutic effect of DD treatment on the frequency and intensity of suicidal ideation in at risk populations has yet to be explored. This is all the more important since there exist effective, short-term cognitive-behavioral treatments (e.g., imagery rehearsal therapy) for idiopathic, chronic, and trauma-related nightmares with well-established success rates in adults (Augedal et al., 2013; Krakow \& Zadra, 2006; Morgenthaler et al., 2018; M. R. Nadorff et al., 2014) and which have also been shown to be effective in young children and adolescents (M. R. Nadorff et al., 2014; Simard \& Nielsen, 2009; St-Onge et al., 2009).

Additional work is also required to clarify the nature and significance of the relation between RD and suicidal ideation. Studies of RD in adult populations (Brown \& Donderi, 1986; Soffer-Dudek et al., 2011; Zadra et al., 1998) have shown that RD are associated with lowered scores on indices of psychological well-being and one study (Gauchat et al., 2009) in adolescents found that the presence of RD was linked to reactive aggression (defined as a defensive reaction to a stimulus which is perceived as threatening (Dodge et al., 1997) among boys. The present results add to the clinical 
importance of these findings and, taken as a whole, point to a need for additional studies of RD and their correlates.

One important limitation of the present study was the relatively small sample that did not allow to reliably control for other potential confounding variables and fully test mediating factors, such as victimization (Marschall-Lévesque et al., 2017) or depression, which is a common risk factor to suicidal ideation and DD (Pigeon et al., 2012).

Nonetheless, among adults the link between DD and suicidal thoughts seem to be maintained even after controlling for depression (Pigeon et al., 2012), which has been replicated in adolescents (Liu, 2004; Russell et al., 2018; Stanley et al., 2017).

Furthermore, the increase noted in suicidal ideations between the age of 12 years old and 13 years old coincides with the transition between elementary school and high school and the numerous changes young adolescents face (Symonds \& Galton, 2014; Virtanen et al., 2019). However, further research is needed to test that hypothesis. Finally, whereas in large community longitudinal cohort studies it may be most appropriate to study suicidal ideation in early adolescence (Marschall-Lévesque et al., 2017), or for specific research questions (Bolanis et al., 2020), such as we also report here, the assessment of actual suicidal behaviors, as they increase gradually with development, may index serious problem behavior later in adolescence. Therefore, it is important that questionnaires on suicidal thoughts and behaviors in longitudinal studies of children and youth also address a broader range of related behaviors in terms of frequency and intensity/seriousness, including actual attempts (Geoffroy et al., 2016; Orri et al., 2020).

Another limitation concerns the use of a retrospective self-report measure of nightmare frequency. While single versus multiple item measures of nightmare frequency have been shown to yield comparable validity coefficients (Kelly \& Mathe, 2020), it is now well established that correlates of retrospective measures of dream recall (including of disturbing dreams) should not be assumed to be correlates of log measures of dream recall collected from the same individuals (Bernstein \& Belicki, 1996; Wood \& Bootzin, 1990; Zadra \& Donderi, 2000). For example, a meta-analysis of studies examining the relationship between dream recall frequency and various personality dimensions found that scores on personality measures were not related to dream recall frequency per se, but rather to people's tendency to retrospectively underestimate or overestimate their dream recall (Beaulieu-Prévost \& Zadra, 2007). Thus, in addition to possible memory distortions and biases that can occur when completing questionnaires, important discrepancies can exist between the information collected via dream questionnaires and dream content and frequency findings obtained through the use of prospective dream journals. Future research efforts should therefore aim to include complementary measures of dream recall (e.g., multiple-item questionnaires as well as prospective dream logs).

In conclusion, although the direction of the association between RD, DD and suicidal ideation remains to be clarified over a longer period of time across adolescence, the present results add to those of previous studies in showing that disturbing and recurrent dreams show significant relations with the dreamer's awaken emotional state (Gauchat et al., 2020; Hartmann, 1998). Similarly, Weinstein and colleagues (2018) postulated that an accumulation of unresolved psychological need frustration might lead to bad dream reoccurrence, which may develop into RD. In the context of at-risk behaviors such as suicide, these observations are particularly important since adolescents are generally reluctant to talk about suicidal ideation, especially when confidentiality is 
not assured (Bernert et al., 2015; Britto et al., 2010; Lothen-Kline et al., 2003). Thus, collecting information on DD and its psychological mechanisms associated with suicide risk may be clinically valuable in the assessment of potential for suicide in at-risk individuals. Finally, work in adolescents and adult populations alike is required to delineate possible beneficial impacts of early treatments aimed at DD or RD on suicidal ideation.

\section{References}

Abe, Y., \& de Kernier, N. (2013). Sleep disturbances from the viewpoint of suicidality: Implications for future psychosocial interventions for youngsters. International Medical Journal, 20(5), 544-551. http://search.ebscohost.com/login.aspx?direct=true\&db=rzh\&AN=92553957\&lan $\mathrm{g}=$ fr\&site $=$ ehost-live

American Psychological Association. (2017). Ethical Principles of Psychologists and Code of Conduct. https://www.apa.org/ethics/code/

Augedal, A. W., Hansen, K. S., Kronhaug, C. R., Harvey, A. G., \& Pallesen, S. (2013). Randomized controlled trials of psychological and pharmacological treatments for nightmares: a meta-analysis. Sleep Medicine Reviews, 17(2), 143-152. https://doi.org/10.1016/j.smrv.2012.06.001

Beaulieu-Prévost, D., \& Zadra, A. (2007). Absorption, psychological boundaries and attitude towards dreams as correlates of dream recall: two decades of research seen through a meta-analysis. Journal of Sleep Research, 16(1), 51-59. https://doi.org/10.1111/j.1365-2869.2007.00572.x

Becker, S. P., Dvorsky, M. R., Holdaway, A. S., \& Luebbe, A. M. (2018). Sleep problems and suicidal behaviors in college students. Journal of Psychiatric Research, 99, 122-128. https://doi.org/10.1016/j.jpsychires.2018.01.009

Bernert, R. A., Hom, M. A., Iwata, N. G., \& Joiner, T. E. (2017). Objectively Assessed Sleep Variability as an Acute Warning Sign of Suicidal Ideation in a Longitudinal Evaluation of Young Adults at High Suicide Risk. Journal of Clinical Psychiatry, 78(6), e678-e687. https://doi.org/10.4088/JCP.16m11193

Bernert, R. A., \& Joiner, T. E. (2007). Sleep disturbances and suicide risk: A review of the literature. Neuropsychiatric Disease and Treatment, 3(6), 735-743. https://doi.org/10.2147/ndt.s1248

Bernert, R. A., Kim, J. S., Iwata, N. G., \& Perlis, M. L. (2015). Sleep disturbances as an evidence-based suicide risk factor. Current Psychiatry Reports, 17(3), 554. https://doi.org/10.1007/s11920-015-0554-4

Bernstein, D. M., \& Belicki, K. (1996). On the Psychometric Properties of Retrospective Dream Content Questionnaires. Imagination, Cognition and Personality, 15(4), 351-364. https://doi.org/10.2190/R1FR-YHF7-EVG9-UDJT

Bolanis, D., Orri, M., Castellanos-Ryan, N., Renaud, J., Montreuil, T., Boivin, M., Vitaro, F., Tremblay, R. E., Turecki, G., Côté, S. M., Séguin, J. R., \& Geoffroy, M.-C. (2020). Cannabis use, depression and suicidal ideation in adolescence: direction of associations in a population based cohort. Journal of Affective Disorders, 274, 1076-1083. https://doi.org/10.1016/j.jad.2020.05.136

Breton, J.-J., Tousignant, M., Bergeron, L., \& Berthiaume, C. (2002). Informant-Specific Correlates of Suicidal Behavior in a Community Survey of 12- to 14-Year-Olds. 
Journal of the American Academy of Child \& Adolescent Psychiatry, 41(6), 723 730. https://doi.org/10.1097/00004583-200206000-00012

Brezo, J., Barker, E. D., Paris, J., Hébert, M., Vitaro, F., Tremblay, R. E., \& Turecki, G. (2008). Childhood Trajectories of Anxiousness and Disruptiveness as Predictors of Suicide Attempts. Archives of Pediatrics \& Adolescent Medicine, 162(11), 1015-1021. https://doi.org/10.1001/archpedi.162.11.1015

Britto, M. T., Tivorsak, T. L., \& Slap, G. B. (2010). Adolescents' Needs for Health Care Privacy. Pediatrics, 126(6), e1469-e1476. https://doi.org/10.1542/peds.2010-0389

Brown, R. J., \& Donderi, D. C. (1986). Dream content and self-reported well-being among recurrent dreamers, past-recurrent dreamers, and nonrecurrent dreamers. Journal of Personality and Social Psychology, 50(3), 612. https://doi.org/10.1037/0022-3514.50.3.612

Bulkeley, K. (2018). The meaningful continuities between dreaming and waking: Results of a blind analysis of a woman's 30-year dream journal. Dreaming, 28(4), 337 350. https://doi.org/10.1037/drm0000083

Camirand, H., Traoré, I., \& Baulne, J. (2016). L'enquête québécoise sur la santé de la population 2014-2015. Institut de la statistique du Québec, Québec, Canada. https://statistique.quebec.ca/en/document/enquete-quebecoise-sur-la-sante-de-lapopulation-2014-2015

Choquet, M., \& Menke, H. (1990). Suicidal thoughts during early adolescence: prevalence, associated troubles and help-seeking behavior. Acta Psychiatrica Scandinavica, 81(2), 170-177. https://doi.org/https://doi.org/10.1111/j.16000447.1990.tb06474.x

Cukrowicz, K. C., Otamendi, A., Pinto, J. V., Bernert, R. A., Krakow, B., \& Joiner Jr, T. E. (2006). The impact of insomnia and sleep disturbances on depression and suicidality. Dreaming, 16(1), 1-10. https://doi.org/10.1037/1053-0797.16.1.1

Dodge, K. A., Lochman, J. E., Harnish, J. D., Bates, J. E., \& Pettit, G. S. (1997). Reactive and proactive aggression in school children and psychiatrically impaired chronically assaultive youth. Journal of Abnormal Psychology, 106(1), 37. https://doi.org/10.1037/0021-843X.106.1.37

Domhoff, G. W. (1993). The repetition of dreams and dream elements: A possible clue to a function of dreams. In M. K. A. Moffitt, \& R. Hoffman (Ed.), The functions of dreams (pp. 293-320). SUNY Press.

Domhoff, G. W. (2011). Dreams are embodied simulations that dramatize conceptions and concerns: the continuity hypothesis in empirical, theoretical, and historical context. https://psycnet.apa.org/record/2011-26292-003

Domhoff, G. W. (2018). The emergence of dreaming: Mind-wandering, embodied simulation, and the default network. Oxford University Press.

Duke, T., \& Davidson, J. (2002). Ordinary and Recurrent Dream Recall of Active, Past and Non-recurrent Dreamers During and After Academic Stress. Dreaming, 12(4), 185-197. https://doi.org/10.1023/a:1021152411010

Gauchat, A., Séguin, J. R., McSween-Cadieux, E., \& Zadra, A. (2015). The content of recurrent dreams in young adolescents. Consciousness and Cognition, 37, 103111. https://doi.org/10.1016/j.concog.2015.08.009 
Gauchat, A., Séguin, J. R., \& Zadra, A. (2014). Prevalence and correlates of disturbed dreaming in children. Pathologie Biologie, 62(5), 311-318. https://doi.org/10.1016/j.patbio.2014.05.016

Gauchat, A., \& Zadra, A. (2012). Prévalence, corrélats et traitements des cauchemars chez les enfants. Pratiques psychologiques, 18(3), 245-264. https://doi.org/10.1016/j.prps.2010.02.001

Gauchat, A., Zadra, A., El-Hourani, M., Parent, S., Tremblay, R. E., \& Séguin, J. R. (2020). Disturbing Dreams and Psychosocial Maladjustment in Children: A Prospective Study of the Moderating Role of Early Negative Emotionality. Frontiers in Neurology, 11. https://doi.org/10.3389/fneur.2020.00762

Gauchat, A., Zadra, A., Tremblay, R. E., Zelazo, P. D., \& Séguin, J. R. (2009). Recurrent dreams and psychosocial adjustment in preteenaged children. Dreaming, 19(2), 75-84. https://doi.org/10.1037/a0016549

Geoffroy, M.-C., Boivin, M., Arseneault, L., Turecki, G., Vitaro, F., Brendgen, M., Renaud, J., Séguin, J. R., Tremblay, R. E., \& Côté, S. M. (2016). Associations Between Peer Victimization and Suicidal Ideation and Suicide Attempt During Adolescence: Results From a Prospective Population-Based Birth Cohort. Journal of the American Academy of Child \& Adolescent Psychiatry, 55(2), 99-105. https://doi.org/10.1016/j.jaac.2015.11.010

Gould, M. S., Greenberg, T., Velting, D. M., \& Shaffer, D. (2003). Youth suicide risk and preventive interventions: a review of the past 10 years. Journal of the American Academy of Child \& Adolescent Psychiatry, 42(4), 386-405. https://doi.org/10.1097/01.CHI.0000046821.95464.CF

Hartmann, E. (1998). Dreams and nightmares: the new theory on the origin and the meaning of dreams. Plenum.

Hasler, B. P., \& Germain, A. (2009). Correlates and treatments of nightmares in adults. Sleep Medicine Clinics, 4(4), 507-517. https://doi.org/10.1016/j.jsmc.2009.07.012

Jetté, M., Desrosiers, H., \& Tremblay, R. E. (1997). "En 2001... J'aurai 5 ans », Enquête auprès des bébés de 5 mois : Rapport préliminaire de l'Étude longitudinale du développement des enfants du Québec (ÉLDEQ) [translation : "In 2001... I'll be 5 years old" Survey of 5 months old infants: Preliminary report from the Québec Longitudinal Study of Childhood Development (QLSCD)]. Ministère de la Santé et des Services sociaux, Gouvernement du Québec.

Kelly, W. E., \& Mathe, J. R. (2020). Comparison of single- and multiple-item nightmare frequency measures. International Journal of Dream Research, 13(2), 136-142. https://doi.org/10.11588/ijodr.2020.2.64362

Krakow, B., \& Zadra, A. (2006). Clinical management of chronic nightmares: imagery rehearsal therapy. Behavioral Sleep Medicine, 4(1), 45-70. https://doi.org/10.1207/s15402010bsm0401_4

Kroth, J., Thompson, L., Jackson, J., Pascali, L., \& Ferreira, M. (2002). Dream characteristics of stock brokers after a major market downturn. Psychological Reports, 90(3 Pt 2), 1097-1100. https://doi.org/10.2466/pr0.2002.90.3c.1097

Lancee, J., \& Schrijnemaekers, N. C. (2013). The association between nightmares and daily distress. Sleep and Biological Rhythms, 11(1), 14-19. https://doi.org/10.1111/j.1479-8425.2012.00586.x 
Levin, R., Fireman, G., \& Nielsen, T. (2010). Disturbed dreaming and emotion dysregulation. Sleep Medicine Clinics, 5(2), 229-239. https://doi.org/10.1016/j.jsmc.2010.01.006

Levin, R., \& Nielsen, T. A. (2007). Disturbed dreaming, posttraumatic stress disorder, and affect distress: A review and neurocognitive model. Psychological Bulletin, 133(3), 482-528. https://doi.org/10.1037/0033-2909.133.3.482

Littlewood, D., Kyle, S. D., Pratt, D., Peters, S., \& Gooding, P. (2017). Examining the role of psychological factors in the relationship between sleep problems and suicide. Clinical Psychology Review, 54, 1-16. https://doi.org/10.1016/j.cpr.2017.03.009

Liu, X. (2004). Sleep and Adolescent Suicidal Behavior. Sleep, 27(7), 1351-1358. https://doi.org/10.1093/sleep/27.7.1351

Liu, X., \& Buysse, D. J. (2006). Sleep and youth suicidal behavior: A neglected field. Current Opinion in Psychiatry, 19(3), 288-293. https://doi.org/10.1097/01.yco.0000218600.40593.18

Liu, X., Chen, H., Bo, Q.-G., Fan, F., \& Jia, C.-X. (2017). Poor sleep quality and nightmares are associated with non-suicidal self-injury in adolescents. European Child \& Adolescent Psychiatry, 26(3), 271-279. https://doi.org/10.1007/s00787016-0885-7

Lothen-Kline, C., Howard, D. E., Hamburger, E. K., Worrell, K. D., \& Boekeloo, B. O. (2003). Truth and consequences: ethics, confidentiality, and disclosure in adolescent longitudinal prevention research. Journal of Adolescent Health, 33(5), 385-394. https://doi.org/10.1016/S1054-139X(03)00184-8

Marschall-Lévesque, S., Castellanos-Ryan, N., Parent, S., Renaud, J., Vitaro, F., Boivin, M., Tremblay, R. E., \& Séguin, J. R. (2017). Victimization, Suicidal Ideation, and Alcohol Use From Age 13 to 15 Years: Support for the Self-Medication Model. Journal of Adolescent Health, 60(4), 380-387. https://doi.org/10.1016/j.jadohealth.2016.09.019

Morgenthaler, T. I., Auerbach, S., Casey, K. R., Kristo, D., Maganti, R., Ramar, K., Zak, R., \& Kartje, R. (2018). Position Paper for the Treatment of Nightmare Disorder in Adults: An American Academy of Sleep Medicine Position Paper. Journal of Clinical Sleep Medicine, 14(06), 1041-1055. https://doi.org/doi:10.5664/jcsm.7178

Nadorff, M. R., Anestis, M. D., Nazem, S., Harris, H. C., \& Winer, E. S. (2014). Sleep disorders and the interpersonal-psychological theory of suicide: Independent pathways to suicidality? Journal of Affective Disorders, 152-154, 505-512. https://doi.org/10.1016/j.jad.2013.10.011

Nadorff, M. R., Lambdin, K. K., \& Germain, A. (2014). Pharmacological and nonpharmacological treatments for nightmare disorder. International Review of Psychiatry, 26(2), 225-236. https://doi.org/10.3109/09540261.2014.888989

Nielsen, T., \& Levin, R. (2007). Nightmares: A new neurocognitive model. Sleep Medicine Reviews, 11(4), 295-310. https://doi.org/10.1016/j.smrv.2007.03.004

Nock, M. K., Borges, G., Bromet, E. J., Alonso, J., Angermeyer, M., Beautrais, A., Bruffaerts, R., Chiu, W. T., de Girolamo, G., Gluzman, S., de Graaf, R., Gureje, O., Haro, J. M., Huang, Y., Karam, E., Kessler, R. C., Lepine, J. P., Levinson, D., Medina-Mora, M. E., Ono, Y., Posada-Villa, J., \& Williams, D. (2008). Cross- 
national prevalence and risk factors for suicidal ideation, plans and attempts. British Journal of Psychiatry, 192(2), 98-105. https://doi.org/10.1192/bjp.bp.107.040113

Nock, M. K., Green, J. G., Hwang, I., McLaughlin, K. A., Sampson, N. A., Zaslavsky, A. M., \& Kessler, R. C. (2013). Prevalence, Correlates, and Treatment of Lifetime Suicidal Behavior Among Adolescents: Results From the National Comorbidity Survey Replication Adolescent Supplement Lifetime Suicidal Behavior Among Adolescents. JAMA Psychiatry, 70(3), 300-310. https://doi.org/10.1001/2013.jamapsychiatry.55

Ophoff, D., Slaats, M. A., Boudewyns, A., Glazemakers, I., Van Hoorenbeeck, K., \& Verhulst, S. L. (2018). Sleep disorders during childhood: a practical review. European Journal of Pediatrics, 177(5), 641-648. https://doi.org/10.1007/s00431018-3116-Z

Orri, M., Scardera, S., Perret, L. C., Bolanis, D., Temcheff, C., Séguin, J. R., Boivin, M., Turecki, G., Tremblay, R. E., Côté, S. M., \& Geoffroy, M.-C. (2020). Mental Health Problems and Risk of Suicidal Ideation and Attempts in Adolescents. Pediatrics, e20193823. https://doi.org/10.1542/peds.2019-3823

Patton, G. C., Coffey, C., Sawyer, S. M., Viner, R. M., Haller, D. M., Bose, K., Vos, T., Ferguson, J., \& Mathers, C. D. (2009). Global patterns of mortality in young people: a systematic analysis of population health data. Lancet, 374(9693), 881892. https://doi.org/10.1016/s0140-6736(09)60741-8

Perou, R., Bitsko, R. H., Blumberg, S. J., Pastor, P., Ghandour, R. M., Gfroerer, J. C., \& Huang, L. (2013). Mental health surveillance among children-United States, 2005-2011 (Morbidity and Mortality Weekly Report, Issue. https://www.cdc.gov/Mmwr/preview/mmwrhtml/su6202a1.htm

Pesant, N., \& Zadra, A. (2006). Dream content and psychological well-being: A longitudinal study of the continuity hypothesis. Journal of Clinical Psychology, 62(1), 111-121. https://doi.org/10.1002/jclp.20212

Pigeon, W. R., Pinquart, M., \& Conner, K. (2012). Meta-analysis of sleep disturbance and suicidal thoughts and behaviors. Journal of Clinical Psychiatry, 73(9), e11601167. https://doi.org/10.4088/JCP.11r07586

Robbins, P. R., \& Tanck, R. H. (1992). A Comparison of Recurrent Dreams Reported from Childhood and Recent Recurrent Dreams. Imagination, Cognition and Personality, 11(3), 259-262. https://doi.org/10.2190/WPDM-99AY-TL2U-JQNG

Robert, G., \& Zadra, A. (2008). Measuring nightmare and bad dream frequency: impact of retrospective and prospective instruments. Journal of Sleep Research, 17(2), 132-139. https://doi.org/10.1111/j.1365-2869.2008.00649.x

Robert, G., \& Zadra, A. (2014). Thematic and Content Analysis of Idiopathic Nightmares and Bad Dreams. Sleep, 37(2), 409-417. https://doi.org/10.5665/sleep.3426

Roberts, J., \& Lennings, C. (2006). Personality, psychopathology and nightmares in young people. Personality and Individual Differences, 41(4), 733-744. https://doi.org/10.1016/j.paid.2006.03.010

Russell, K., Rasmussen, S., \& Hunter, S. C. (2018). Insomnia and Nightmares as Markers of Risk for Suicidal Ideation in Young People: Investigating the Role of Defeat and Entrapment. Journal of Clinical Sleep Medicine, 14(5), 775-784. https://doi.org/10.5664/jcsm.7104 
Sandman, N., Valli, K., Kronholm, E., Ollila, H. M., Revonsuo, A., Laatikainen, T., \& Paunio, T. (2013). Nightmares: Prevalence among the Finnish General Adult Population and War Veterans during 1972-2007. Sleep, 36(7), 1041-1050. https://doi.org/10.5665/sleep.2806

Scarpelli, S., Bartolacci, C., D'Atri, A., Gorgoni, M., \& De Gennaro, L. (2019). The Functional Role of Dreaming in Emotional Processes. Frontiers in Psychology, 10, 459. https://doi.org/10.3389/fpsyg.2019.00459

Schredl, M., \& Hofmann, F. (2003). Continuity between waking activities and dream activities. Consciousness and Cognition, 12(2), 298-308. https://doi.org/10.1016/S1053-8100(02)00072-7

Simard, V., \& Nielsen, T. (2009). Adaptation of imagery rehearsal therapy for nightmares in children: A brief report. Psychotherapy: Theory, Research, Practice, Training, 46(4), 492. https://doi.org/10.1037/a0017945

Simard, V., Nielsen, T. A., Tremblay, R. E., Boivin, M., \& Montplaisir, J. Y. (2008). Longitudinal Study of Bad Dreams in Preschool-Aged Children: Prevalence, Demographic Correlates, Risk and Protective Factors. Sleep, 31(1), 62-70. https://doi.org/10.1093/sleep/31.1.62

Sjöström, N., Hetta, J., \& Waern, M. (2009). Persistent nightmares are associated with repeat suicide attempt: A prospective study. Psychiatry Research, 170(2-3), 208211. https://doi.org/10.1016/j.psychres.2008.09.006

Soffer-Dudek, N., \& Shahar, G. (2009). What are sleep-related experiences? Associations with transliminality, psychological distress, and life stress. Consciousness and Cognition, 18(4), 891-904. https://doi.org/10.1016/j.concog.2008.07.007

Soffer-Dudek, N., Shalev, H., Shiber, A., \& Shahar, G. (2011). Role of severe psychopathology in sleep-related experiences: A pilot study. Dreaming, 21(2), 148-156. https://doi.org/10.1037/a0022865

St-Onge, M., Mercier, P., \& De Koninck, J. (2009). Imagery rehearsal therapy for frequent nightmares in children. Behavioral Sleep Medicine, 7(2), 81-98. https://doi.org/10.1080/15402000902762360

Stanley, I. H., Hom, M. A., Luby, J. L., Joshi, P. T., Wagner, K. D., Emslie, G. J., Walkup, J. T., Axelson, D. A., \& Joiner, T. E. (2017). Comorbid sleep disorders and suicide risk among children and adolescents with bipolar disorder. Journal of Psychiatric Research, 95, 54-59. https://doi.org/10.1016/j.jpsychires.2017.07.027

Symonds, J. E., \& Galton, M. (2014). Moving to the next school at age 10-14 years: An international review of psychological development at school transition. Review of Education, 2(1), 1-27. https://doi.org/10.1002/rev3.3021

Tanskanen, A., Tuomilehto, J., Viinamäki, H., Vartiainen, E., Lehtonen, J., \& Puska, P. (2001). Nightmares as predictors of suicide. Sleep, 24(7), 845-848. https://doi.org/10.1093/sleep/24.7.845

Virtanen, T., Vasalampi, K., Torppa, M., Lerkkanen, M.-K., \& Nurmi, J.-E. (2019). Changes in students' psychological well-being during transition from primary school to lower secondary school: A person-centered approach. Learning and Individual Differences, 69, 138-149. https://doi.org/10.1016/j.lindif.2018.12.001

Weinstein, N., Campbell, R., \& Vansteenkiste, M. (2018). Linking psychological need experiences to daily and recurring dreams. Motivation and Emotion, 42(1), 50-63. https://doi.org/10.1007/s11031-017-9656-0 
Wong, M. M., Brower, K. J., \& Zucker, R. A. (2011). Sleep problems, suicidal ideation, and self-harm behaviors in adolescence. Journal of Psychiatric Research, 45(4), 505-511. https://doi.org/10.1016/j.jpsychires.2010.09.005

Wood, J. M., \& Bootzin, R. R. (1990). The prevalence of nightmares and their independence from anxiety. Journal of Abnormal Psychology, 99(1), 64-68. https://doi.org/10.1037/0021-843X.99.1.64

Zadra, A., Desjardins, S., \& Marcotte, E. (2006). Evolutionary function of dreams: A test of the threat simulation theory in recurrent dreams. Consciousness and Cognition, 15(2), 450-463. https://doi.org/10.1016/j.concog.2005.02.002

Zadra, A., \& Donderi, D. C. (2000). Nightmares and bad dreams: Their prevalence and relationship to well-being. Journal of Abnormal Psychology, 109(2), 273-281. https://doi.org/10.1037/0021-843X.109.2.273

Zadra, A. L., O'Brien, S. A., \& Donderi, D. (1998). Dream content, dream recurrence and well-being: A replication with a younger sample. Imagination, Cognition and Personality, 17(4), 293-311. https://doi.org/10.2190/LLXL-D4DB-9CP5-BRGT 